\title{
HEAT LOSS THROUGH COVERING LAYER
}

\author{
Yi Zhang, Chengwei Ma ${ }^{*}$, Junfang Zhang, Midao Qin, Ruichun Liu \\ * Corresponding author. Director of Key Lab of Agricultural Bio-environment Engineering, \\ Ministry of Agriculture, P. R. China, 17 Tsinghua East Road, Beijing, 100083, P. R. China, \\ Email:macwbs@cau.edu.cn
}

Abstract: A model of heat transfer through greenhouse covering materials was developed in this study. The influences of the thermal properties of covering materials, the construct parameters of greenhouse and the environment inner and outer of greenhouse were completely considered in the model. Heat transfer flux density through covering layer can be simulated and forecasted by using this model. The simulated values of heat transfer flux density through covering layer were in accordance with the values got from some experiments. This model can be used for many purposes, such as greenhouse design, analysis and control for thermal environment in greenhouse.

Keywords: greenhouse; covering material; heat transfer; heat radiation; theoretical model

\section{INTRODUCTION}

More than $70 \%$ of the energy consumption in a greenhouse in winter is owing to the heat loss through covering layer. For this reason, an accurate analytical prediction of the heat loss through covering material is the key point for predicting energy consumption in a greenhouse.

In the past, some methods applied to analyzing the heat transfer through ordinary building materials were used to calculate the heat transfer through greenhouse covering material (Papadakis et al., 2000). But heat radiation through covering material is different from ordinary building materials. Some models have been established and developed, which considered the transmission of infrared radiation through covering layer and the direct 
radiant heat exchange between inner and outer of a greenhouse (Feuilloley et al., 1996; Li et al., 2004).

The objective of this study was to develop a heat transfer model which can exactly reflect thermal properties of covering materials, greenhouse structures and working conditions.

\begin{tabular}{|c|c|c|c|}
\hline \multicolumn{4}{|c|}{ notation } \\
\hline$t, T$ & air temperature, $\square, \mathrm{K}$ & $\rho$ & $\begin{array}{l}\text { reflectance of a surface for thermal } \\
\text { radiation }\end{array}$ \\
\hline$F$ & area, $\mathrm{m}^{2}$ & $\varepsilon$ & $\begin{array}{l}\text { emittance of a surface for thermal } \\
\text { radiation }\end{array}$ \\
\hline$J$ & $\begin{array}{l}\text { effective radiation heat flux density, } \\
\mathrm{W} / \mathrm{m}^{2}\end{array}$ & $\sigma_{\mathrm{b}}$ & $\begin{array}{l}\text { black radiation constant }\left(=5.67 \times 10^{-8}\right) \text {, } \\
\mathrm{W} /\left(\mathrm{m}^{2} \cdot \mathrm{K}^{4}\right)\end{array}$ \\
\hline$G$ & radiation heat flux density, $\mathrm{W} / \mathrm{m}^{2}$ & $\alpha$ & $\begin{array}{l}\text { convective heat transfer coefficient, } \\
\mathrm{W} /\left(\mathrm{m}^{2} \cdot \square\right)\end{array}$ \\
\hline$Q, q$ & convective heat flux density, $\mathrm{W}, \mathrm{W} / \mathrm{m}^{2}$ & $\phi$ & radiation shape factor \\
\hline$v$ & wind speed, $\mathrm{m} / \mathrm{s}$ & $\tau$ & $\begin{array}{l}\text { transmittance of a surface for thermal } \\
\text { radiation }\end{array}$ \\
\hline$\beta$ & ratio of heat prevention $\left(=F_{\mathrm{s}} / F_{1}\right)$ & $K$ & $\begin{array}{l}\text { overall coefficient of heat transfer of } \\
\text { covering layer, } \mathrm{W} /\left(\mathrm{m}^{2} \cdot \mathrm{K}\right)\end{array}$ \\
\hline \multicolumn{4}{|c|}{ subscripts } \\
\hline $\mathrm{v}$ & sky & $\mathrm{i}$ & inside \\
\hline s & ground & $1 \mathrm{u}$ & outside surface of covering \\
\hline 1 & covering & $1 d$ & inside surface of covering \\
\hline $\mathrm{o}$ & outside & & \\
\hline
\end{tabular}

\section{HEAT TRANSFER MODEL OF GREENHOUSE COVERING LAYER}

A heat transfer model of greenhouse covering layer is illustrated schematically in Figure 1.
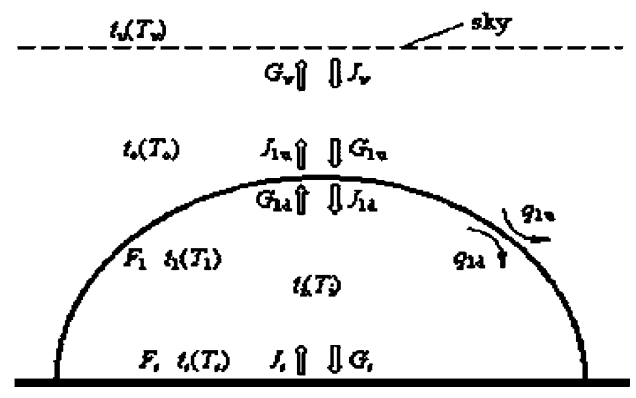

Figure 1. Sketch of heat transfer model of greenhouse covering layer 
The method of analyzing effective radiation was used in this study. For each surface related to radiant heat transfer, effective radiation heat flux and radiation heat flux toward the surface could be calculated as follows.

$$
\begin{aligned}
& J_{\mathrm{v}}=\varepsilon_{\mathrm{v}} \sigma_{\mathrm{b}} T_{\mathrm{v}}^{4}+G_{\mathrm{v}} \rho_{\mathrm{v}} \\
& G_{\mathrm{v}}=J_{1 \mathrm{u}} \phi_{1 \mathrm{u}, \mathrm{v}} F_{1} / F_{\mathrm{v}} \\
& J_{1 \mathrm{u}}=\varepsilon_{1 \mathrm{u}} \sigma_{\mathrm{b}} T_{1}^{4}+G_{1 \mathrm{u}} \rho_{1 \mathrm{u}}+G_{1 \mathrm{~d}} \tau_{1} \\
& G_{1 \mathrm{u}}=J_{\mathrm{v}} \phi_{\mathrm{v}, 1 \mathrm{u}} F_{\mathrm{v}} / F_{1}+J_{1 \mathrm{u}} \phi_{1 \mathrm{u}, 1 \mathrm{u}} \\
& J_{1 \mathrm{~d}}=\varepsilon_{1 \mathrm{~d}} \sigma_{\mathrm{b}} T_{1}^{4}+G_{1 \mathrm{~d}} \rho_{1 \mathrm{~d}}+G_{1 \mathrm{u}} \tau_{1} \\
& G_{1 \mathrm{~d}}=J_{\mathrm{s}} \phi_{\mathrm{s}, 1 \mathrm{~d}} F_{\mathrm{s}} / F_{1}+J_{1 \mathrm{~d}} \phi_{1 \mathrm{~d}, 1 \mathrm{~d}} \\
& J_{\mathrm{s}}=\varepsilon_{\mathrm{s}} \sigma_{\mathrm{b}} T_{\mathrm{s}}^{4}+G_{\mathrm{s}} \rho_{\mathrm{s}} \\
& G_{\mathrm{s}}=J_{1 \mathrm{~d}} \phi_{1 \mathrm{~d}, \mathrm{~s}} F_{1} / F_{\mathrm{s}}
\end{aligned}
$$

The sky temperature has relationships with many factors such as air temperature, so there are lots of methods to calculate it, for example, $T_{\mathrm{v}}=0.0552 T_{\mathrm{o}}^{1.5}$.

Where there are 9 unknown quantities that are 8 radiation heat fluxes and covering temperature $T_{1}\left(t_{1}\right)$ in above equations. In order to calculate $T_{1}\left(t_{1}\right)$, energy-balance equation of the covering layer and convective heat flux equations must be researched.

Convective heat flux between air and surface covering is given by Eqn. (9-12) (Roy et al., 2002):

$$
\begin{aligned}
& Q_{1 \mathrm{u}}= F_{1} q_{1 \mathrm{u}}=F_{1} \alpha_{1 \mathrm{u}}\left(T_{1}-T_{\mathrm{o}}\right) \\
& \alpha_{1 \mathrm{u}}=7.2+3.84 v_{\mathrm{o}} \\
& Q_{1 \mathrm{~d}}= F_{1} q_{1 \mathrm{~d}}=F_{1} \alpha_{1 \mathrm{~d}}\left(T_{\mathrm{i}}-T_{1}\right) \\
& \alpha_{1 \mathrm{~d}}=2.21\left(T_{\mathrm{i}}-T_{1}\right)^{0.33}
\end{aligned}
$$

According to the principle of energy conservation, covering temperature is calculated from

$$
\left(G_{1 \mathrm{u}}+G_{1 \mathrm{~d}}+q_{1 \mathrm{~d}}\right)-\left(J_{1 \mathrm{u}}+J_{1 \mathrm{~d}}+q_{1 \mathrm{u}}\right)=0
$$

\section{CONCLUSIONS (SIMULATED CALCULATION AND EXPERIMENTAL VERIFICATION)}

The author worked out the computer program of covering heat transfer which was based on the heat transfer model. Simultaneously, some heat transfer experiments of a few kinds of covering materials were tried out in a laboratory using test apparatus (Zhang et al., 2005). Each group of 
simulation and experiment was at the same environmental conditions, so the results represented in table 1 could be compared.

Table 11. Simulated values and experimental results

\begin{tabular}{|c|c|c|c|c|c|c|c|}
\hline \multirow{4}{*}{$\begin{array}{l}\text { Covering material } \\
\\
\mathrm{PE}\end{array}$} & \multicolumn{5}{|c|}{ Environmental conditions } & \multicolumn{2}{|c|}{ Heat flux density through covering } \\
\hline & \multirow{3}{*}{$\frac{t_{\mathrm{o}} / \square}{-1.3}$} & \multirow{3}{*}{$\frac{t_{\mathrm{i}} / \square}{27.8}$} & \multirow{3}{*}{$\frac{v_{\mathrm{o}} / \mathrm{m} \cdot \mathrm{s}^{-1}}{1.0}$} & \multirow{3}{*}{$\frac{t_{\mathrm{v}} / \square}{-27.8}$} & \multirow{3}{*}{$\frac{t_{\mathrm{s}} / \square}{27.2}$} & Experimental & Simulated \\
\hline & & & & & & \multicolumn{2}{|c|}{$q_{\mathrm{w}} / \mathrm{W} \cdot \mathrm{m}^{-2}$} \\
\hline & & & & & & 253.2 & 235.9 \\
\hline PE & -2.5 & 27.0 & 2.1 & -32.8 & 26.2 & 273.2 & 255.7 \\
\hline $\mathrm{PVC}$ & -2.2 & 25.0 & 4.0 & -27.2 & 23.6 & 231.5 & 226.0 \\
\hline Glass & -1.3 & 27.5 & 1.0 & -28.3 & 26.7 & 190.1 & 192.8 \\
\hline Glass & -2.3 & 28.3 & 3.0 & -30.3 & 27.1 & 232.3 & 226.0 \\
\hline
\end{tabular}

For the heat flux density through covering, simulated predictive values are in accordance with the results got from the experiments, with the max relative error below $10 \%$.

A heat transfer model of greenhouse covering layer is developed in this paper. The influence of the greenhouse structure on the covering heat transfer is reflected in the model. Radiant and convective heat flux density inside and outside covering could be simulated and calculated by this model, then overall energy consumption could be predicted.

\section{ACKNOWLEDGEMENTS}

The author is indebted to Beijing Municipal Commission of Education for the financial support by the cooperation program (XK100190550).

\section{REFERENCES}

G. Papadakis, D. Briassoulis, G. Scarascia Mugnozza, et al. Radiometric and Thermal Properties of and Testing Methods for Greenhouse Covering Materials. J. agric. Engng. Res., 2000, 77(1): 7-38

P. Feuilloley, G. Issanchou. Greenhouse Covering Materials Measurement and Modeling of Thermal Properties Using the Hot Box Method, and Condensation Effects. J. agric. Engng. Res., 1996, 65: 129-142

Shuhai Li, Chengwei Ma, Junfang Zhang, et al. Thermal model of multi-span greenhouses with multi-layer covers. Transactions of the CSAE, 2004, 20(3): 217-221

J.C. Roy, T. Boulard, C. Kittas, et al. Convective and Ventilation Transfers in Greenhouses, Part 1: the Greenhouse considered as a perfectly stirred tank. Biosystem Engineering. 2002, 83(1): $1-20$

Junfang Zhang, Chengwei Ma, Midao Qin, et al. Research and development of the test apparatus for measuring the overall heat transfer coefficient of greenhouse covering materials. Transactions of the CSAE, 2005, 21(11): 141-145 